\title{
Research on Microteaching Management Model Under Informatization Background
}

\author{
Li Bin \\ Baicheng Normal University, Baicheng, 137000, China \\ email: 22269702@qq.com
}

Keywords: Informatization; Network Platform; Microteaching; Management Model

\begin{abstract}
This paper comprehensively sorts out microteaching and network platform, summarizes the main disadvantages of current microteaching management model, and explores the compatibility between network platform and microteaching, thus providing early support for this research. Secondly, based on the knowledge management theory, independent learning theory and information technology theory, this paper gives an analysis of the feasibility of realizing microteaching management by network platform. At last, this paper puts forward a trinity of network platform-supported microteaching management model, namely, the teacher-instructed learning model, the self-learning model and the collaborative learning model.
\end{abstract}

\section{Introduction}

As an optimization model for training normal university students' classroom teaching skills, microteaching deeply reflects the thoughts of modern teaching theory, including Gagne's theory of classifying learning results, Dewey's "learning by doing” theory, Babanski's theory of classifying cognitive activities, and Lasswell's communication theory. [1]At the same time, through literature and personal experience, the author finds that some problems existing in microteaching practice have seriously affected the quality of microteaching. To solve these problems, microteaching must be optimized and innovated so as to improve the training effect of the teaching skills of normal university students.[2] Through the research of this subject, it is expected to deepen the rational understanding of microteaching management in relevant theoretical and practical circles and promote the optimization of microteaching.

\section{Definition of Microteaching}

The concept of microteaching was proposed by Dr. Dwight W. Allen of Stanford university, who defined it as "a controlled internship system, which makes it possible for normal university students to focus on solving a specific teaching behavior or to learn under controlled conditions". As a training method to improve the teaching skills of normal university students and their teaching level, microteaching originated from the United States in the 1960s, and was introduced into China in the 1980s.[3] It was once translated by domestic scholars as "microteaching", "small group teaching" and "mini-teaching", and was gradually referred to as "microteaching”. [4] Among them, "micro" refers to small group teaching, with limited selection of teaching contents, or to decompose "large" teaching skills into several "small" teaching skills. The meaning of "Ge" is derived from the Chinese idiom "learning from facts", which refers to the understanding of things and the acquisition of knowledge. [5] Here, it can be understood that teachers and students jointly study and discuss the problems in teaching skills training, so as to realize a result of teaching benefits teachers as well as students.

\section{Main Problems Existing in Microteaching}

It is commonly acknowledged that the ways and means for normal university students to improve their classroom teaching skills are mainly microteaching training and education internship 
arranged by the school before graduation. However, education internship has limited time for students to actually walk on the platform and deliver several lectures. Moreover, education internship focuses on the comprehensive training of interns, including classroom classes, head teacher work, extracurricular tutoring work, etc., which is not mainly aimed at the students' classroom teaching skills. This highlights the importance and goal of using microteaching to cultivate the teaching skills of normal university students. However, from the author's practical experience and the in-depth study of microteaching, microteaching management is of paramount significance for the development of teachers' professional skills. However, the implementation effect in various normal universities is far from satisfactory. In other words, there are many practical problems that cannot be ignored in the process of microteaching management for normal university students at present.

\subsection{Limited training time and unsatisfactory effect}

The microteaching system cannot meet the needs of a large number of normal university students which result in limited training time and unsatisfactory effect of microteaching. On the one hand, the number of microteaching system owned by normal universities is not enough to satisfy the microteaching expansion scale. In addition, most universities arrange microteaching training only for junior and senior, and teachers and students must be trained repeatedly at the same time and place, which results in very little training time for each student. Due to the lack of class hours caused by the limitation of equipment and site, students cannot deeply understand the spirit and thought of microteaching, and the training process is only a process, which cannot meet the basic requirements of microteaching and realize the goal of using microteaching to improve the teaching ability of students in normal universities. On the other hand, microteaching emphasizes various teaching feedback and repeated teaching. However, in traditional microteaching system, the teaching process of recording and playback are recorded by the same set of devices, students can't watch and reflect anywhere and anytime according to their needs. Besides, teachers and peer exchange of experience could be limited, thus affect the quality of microteaching.

\subsection{Single training model}

Based on a lot of researches and the author's personal experience, it can be seen that many universities' microteaching training is carried out mechanically according to the step-by-step process, and the training process is very formalized. Students cannot truly get a demand of the theoretical thoughts of microteaching, nor can they truly improve their classroom teaching skills in the process of simulation teaching. In addition, this training model cannot be flexible according to the needs of teaching. If any teaching content, research topic, teaching method or teaching form is carried out according to this model, it is just a rigid training which can neither arouse students' interest in teaching nor improve the quality of micro-teaching. The single training model of microteaching is not conducive to the research and promotion of microteaching.

\subsection{Students lack independence and flexibility in learning}

The present microteaching training mainly in the form of group, and the time and energy invested in the teachers-instructed simulation training process are huge. The face-to-face limited guidance in class can't effectively help students improve teaching practice which lack of continuous help and guidance. Moreover, the face-to-face experience communication between students is single in form, and sometimes they just put forward several improvement suggestions at random. The communication is not sufficient enough, and the centralized discussion will be only limited by the classroom teaching time and cannot be analyzed and evaluated freely, continuously and deeply. In addition, the interaction between groups is not enough. The overall microteaching and training of the class lacks unity and comprehensiveness, and students cannot get feedback from the whole class. All these aspects affect students' enthusiasm to participate in microteaching, which further reduces the efficiency of micro-teaching. 


\section{Network Platform-supported Microteaching Management Model}

\subsection{Theoretical basis of network platform-supported microteaching management}

Through in-depth analysis of the functional characteristics of the network platform, the main features of microteaching and the relevant theoretical essence of education teaching, the author thinks that the most important theoretical basis for microteaching management under the network platform environment is knowledge management theory. Knowledge management theory points out that knowledge is divided into two major categories of explicit knowledge and implicit knowledge. Explicit knowledge means you can learn, store, transmit and share by words, language and data, while implicit knowledge is acquired by practice and experience which is not easy to save, transfer, or master. It can be perceived but cannot be described with words. In the process of microteaching, the trainers learn and master microteaching theories, including explicit knowledge such as education, psychology, and teaching theory. The teaching skills applied in classroom teaching are implicit knowledge. The key of this research is to build a platform for knowledge and experience exchange between teachers and students, students and groups through the network platform. To "internalize" the implicit knowledge of teachers and students into the implicit knowledge system of individuals, thus realizing the innovation of micro-teaching management.

\subsection{Management model construction of network platform-supported microteaching}

Network platform-supported microteaching is a method, approach or means chosen to achieve certain teaching purposes or to solve the problems existing in current microteaching management under the technical support of network platform. At the micro level, microteaching management is concrete and specific. In this paper, the network platform-supported microteaching management is divided into the independent lesson preparation, collaborative learning model and teacher-instructed model. The relations of these three models are not mutually antagonistic, but are mutually independent and unified.

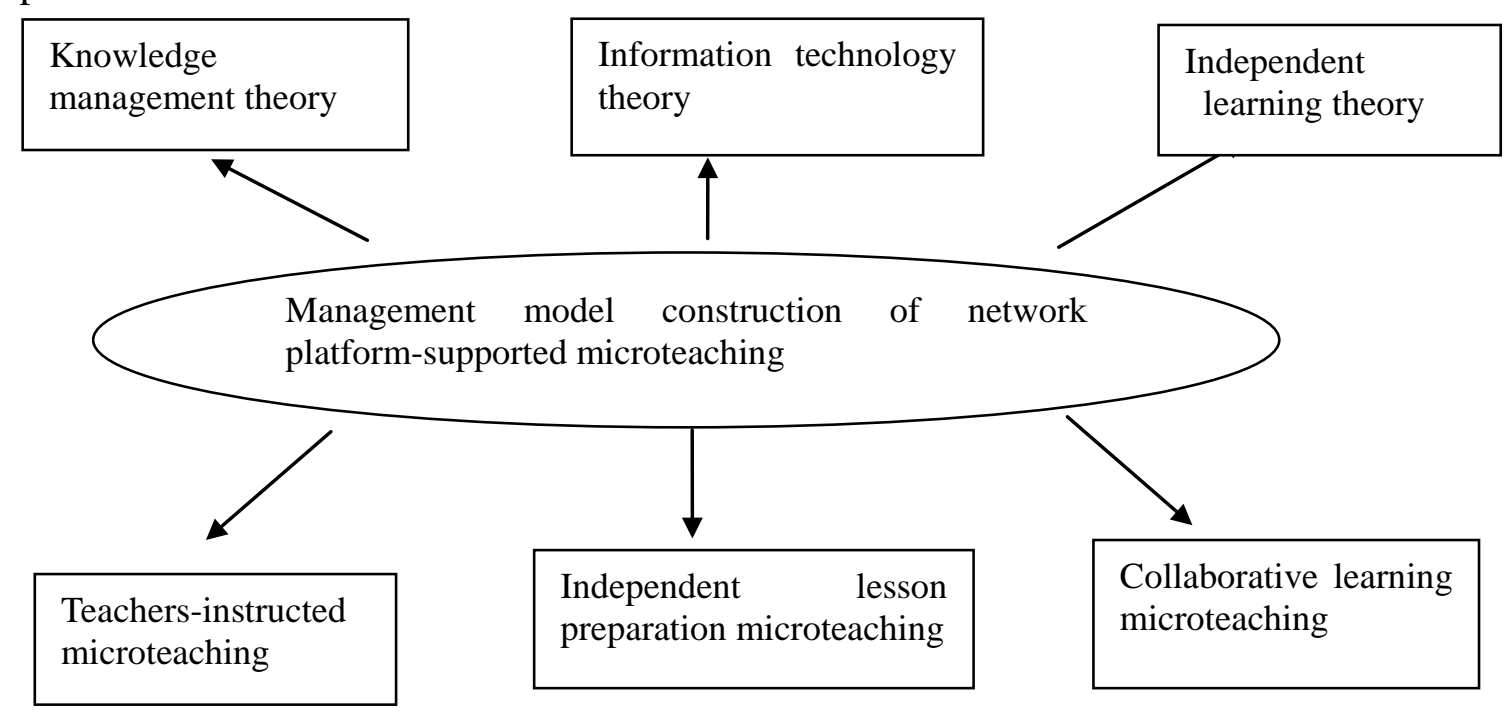

\subsubsection{Teachers-instructed microteaching supported by network platform}

Teachers-instructed microteaching supported by network platform refers to the microteaching model which is conducted on the network platform with the guidance of teachers. It can not only reflect the management features of general classroom teaching, but also demonstrate the unique charm of micro-teaching. The basic process of teachers-instructed microteaching includes theory learning, observation and demonstration, lesson plans writing, skill training, interactive discussion and teaching again. In the stage of theoretical learning, cramming method of teaching is not recommended, because trainees' knowledge structure cannot just rely on listening. The author believes that the only combination of explanation and demonstration can present a vivid teaching. By instructing teachers to improve teaching methods and enlighten teaching, better results can be 
obtained. In the observation and demonstration stage, the teacher guides the trainees to watch the demonstration videos. It is important to use the microteaching theory to deeply analyze, discuss and communicate the feelings after watching and form the mental process of teaching skills, which can highlight the significance of learning the microteaching theory in the first step. Then, when writing the teaching plan, the guidance teacher should work with the trainees to revise the pre-written microteaching plan according to the teaching theory and teaching content, that is, the pre-implementation feedback. Moreover, the guidance teacher can offer trainees their own teaching experience, help them clarify the teaching plan and promote their reflection. When watching the live video of teaching and group feedback evaluation, it should be carried out according to the skill theory of microteaching under the premise of teachers' assistance. In the second training, it should be improved and perfected specifically according to the content of the course evaluation.

\subsubsection{Independent lesson preparation microteaching supported by network platform}

The network platform-supported microteaching with independent lesson preparation refers to the way in which normal university students or in-service teachers take the initiative to exert their subjective initiative and master teaching skills through independent learning and self-training. This approach applies to two situations: first, the trainee is fully self-aware. In this state, trainees can understand their shortcomings in classroom teaching according to the evaluation of classroom teaching, so as to have a purposeful self-training based on their shortcomings. In the second case, trainees explore the ideal teaching model, which is more suitable for new teachers to improve teaching skills or old teachers to study teaching. That is to say, teachers design and organize classroom contents before class, conduct small-scale simulation teaching, and accumulate experience for improving the teaching quality of large classes.

\subsubsection{Collaborative learning microteaching supported by network platform}

The network platform provides students with a platform for collaborative learning and communication. In microteaching management process, each trainee is required to be ready to take turns as a mentor, which puts a higher requirement on them. They should possess necessary qualities of a teacher such as active learning attitude and strong sense of responsibility, familiarity with microteaching process, basic proficiency in microteaching skills organization and evaluation methods, and certain organizational and leadership skills. Firstly, in the collective learning stage, under the guidance of the tutor (the student who serves as the instructor), each group member should study the relevant theoretical knowledge of microteaching, watch the demonstration video in the resource library, and compile the microteaching plan. Then, in the group practice stage, each member of the group chooses the appropriate time and place to carry out the training, and uses the software to repeatedly watch the links of teaching videos, group discussion and self-evaluation, and finally carries out the process of revising the teaching plan and retraining. Of course, the teaching videos can not only be watched by the members of the group, but also be observed and evaluated by other groups. Theoretically, this method can improve the efficiency of feedback and evaluation to some extent.

\section{Conclusion}

The training object of microteaching is normal university students or in-service teachers, aiming at improving their classroom teaching skills. The microteaching management model supported by the network platform designed by the author is also applicable to normal university students or in-service teachers, and its main advantage is the convenience of implementation and deep interactivity of evaluation. Based on the theories of knowledge management and other relevant theories, the author constructed a microteaching management model with the help of the network platform in the form of teacher guidance, independent lesson preparation and cooperative learning, which are both independent and sequentially developed. These would constitute some valuable reference for future microteaching researchers. 


\section{References}

[1] Microteaching Revisited: Using Technology to Enhance the Professional Development of Pre-Service Teachers[J]. ThomasJ. Diana. The Clearing House: A Journal of Educational Strategies, Issues and Ideas. 2013 (4)

[2] Micro-teaching research, theory and practice. C Tumey Sydney. 1973

[3] Evaluation Conept: Leonardo Project Microteaching. BirgitZens, Dagmar Strohmeier, Ralph Reimann, Christiane Spiel. 2005

[4] Videotaped Microteaching: Bridging the Gap from the University to the Classroom. Rebecca B, Elizabeth W, Thomson W. The Teacher Educator. 2009

[5] Creating a Microteaching Evaluation Form: the Needed Evaluation Criteria. Karthigeyan Subramaniam. Education. 2006 